\title{
STEADY AND DYNAMIC STATES ANALYSIS OF INDUCTION MOTOR: FEA APPROACH
}

\author{
E. C. Abunike1, ${ }^{1,}$, O. I. Okoro ${ }^{2}$ and G. D.Umoh ${ }^{3}$

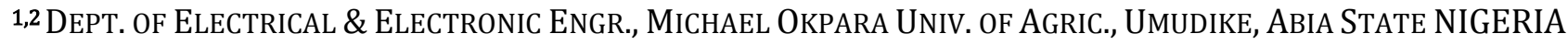 \\ 3 DePt. of EleCtrical \& ElECTRONIC ENGR, MARITIME ACADEMy of NigERIA, ORON AKWA IBOM STATE, NiGERIA \\ E-mail addresses: ${ }^{1}$ abunikeweta@gmail.com, ${ }^{2}$ oiokoro@yahoo.co.uk, ${ }^{3}$ umohgideon@gmail.com
}

\begin{abstract}
This paper deals with the steady and dynamic states analysis of induction motor using finite element analysis (FEA) approach. The motor has aluminum rotor bars and is designed for direct-on-line operation at $50 \mathrm{~Hz}$. A study of the losses occurring in the motor performed at operating frequency of $50 \mathrm{~Hz}$ showed that stator copper loss and rotor copper loss were higher than the other types of losses like the stray, iron core, frictional and windage losses. The motor efficiency based on material design was also studied at operating temperature. The materials considered in this paper are iron, nickel and cobalt. It was observed that iron at $75^{\circ} \mathrm{C}$ provided the best efficiency than other materials. The steady and dynamic states characteristics of the motor at rated load and on no-load conditions were observed. The flux levels at these loading conditions were also monitored.
\end{abstract}

Key words. Three phase Induction Motor, Steady state and Dynamic Response, Flux Levels, FEA, Loading conditions.

\section{INTRODUCTION}

The steady state and dynamic model of induction machine and its simulation plays a vital role in the validation of design process of the motor-drive systems, eliminating inadvertent design mistakes and the resulting errors in the prototype construction and testing [1]. The steady state modeling of Induction machines is not new and has received a considerable attention from researchers dated far back as the machine itself [2-4]. On the other hand, the transient mathematical modeling of Induction machines continues to receive enormous attention and will continue to do so because of the vital effect the transient behavior of the Induction machine has on the overall performance of the system to which it forms a component part. Unlike the steady state modeling, transient modeling proves to be more complex both in the definition of suitable forms of equations and in the application of appropriate numerical methods needed for the solution of same [5]. Numerical methods are more suitable for the electromagnetic field analysis of electric machines. There are a number of numerical methods available for the analysis of electromagnetic field problems. A few of them are moments method (MM), montecarlo method (MCM), finite difference method (FDM) [6], boundary element method (BEM) [7] and finite element method (FEM) [8].These methods have their advantages and disadvantages.
However, finite element method incorporates most of the advantages of the other two methods without incurring significant disadvantages; especially for the analysis of electric machines where many factors need to be considered, such as complex geometries, magnetic and electric materials, induced currents, coupling of thermal and mechanical effects, etc. In such cases, the finite element method is more suitable. For example, the finite difference method is not easily applicable to the field involving rapid changes of the gradient or complex geometries. Nodal distribution can be very inefficient. This is not so with finite elements. Equally, boundary element method is not efficient at handling non-linear materials [9]. Finite element method is well suited for the analysis involved with nonlinearities. It can be used for solving both linear and non-linear field problems including simple and complex geometries. Thus it is well recognized that finite element method offers considerable advantages in electrical machine analysis [9-10].

The FEA was first introduced for the computation of magnetic field in nonlinear electromagnetic devices by Chari and Silvester in 1970's [11]. It was mainly for solving nonlinear magnetostatic problems. Hannala and MacDonald pioneered the numerical calculation of transient phenomenon during the operation of electric machines [12].

\footnotetext{
* Corresponding author tel: +234-806-806-6687
} 
FEA is a technique based on the magnetic field analysis that takes into account the magnetic circuit geometry, spatial distribution of stator windings and rotor bars, existing slots around air gap, and nonlinear behavior of ferromagnetic materials. By the introduction of the FEA, numerical field calculation approach has become a strong alternative in the design and analysis of electrical machines and many performance outcomes can be assessed. Intensive knowledge of FEA could be found in [13-15].

In this paper, ANSYS Maxwell which is a commercial electromagnetic field simulation software used for designing and analyzing 3-D and 2-D electromagnetic and electromechanical devices, including motors, actuators, transformers, sensors and coils will be used. Rotating Machinery Expert (RMxprt) which is another commercial tool developed by ANSYS will also be used. It is a template-based electrical machine design tool that provides fast, analytical calculations of machine performance and 2-D and 3-D geometry creation for detailed finite element calculations in ANSYS Maxwell. In order to provide classical motor performance calculations, RMxprt will automatically generate a complete transfer of the 2-D geometry of the motor, including all properties, to Maxwell for detailed finite element analysis calculations. ANSYS Maxwell-2D and RMxprt software tools will be used to create a squirrel cage motor design and analyze the performance behaviours.

\section{FINITE ELEMENT ANALYSIS MODEL}

Electromagnetic field analysis can be represented as the problem of solving Maxwell's equations subjected to certain boundary conditions. These equations state the relationships between the fundamental electromagnetic field quantities as follows:

$$
\begin{aligned}
& \nabla \times H=j+\frac{\partial D}{\partial t} \\
& \nabla \times E=-\frac{\partial B}{\partial t}+\nabla \times(v \times B) \\
& \nabla . D=\rho \\
& \nabla \cdot B=0
\end{aligned}
$$

In (1) to (5), $E, D$ - are electric field intensity and electric flux density respectively, $H, B$ - are the magnetic field intensity and magnetic flux density, respectively, $J$ is the current density, $V$ - is the velocity of the conductor with respect to $B$, and $\rho$ - is the electric charge density

In modeling of the motor, the position of the moving parts of the motor must be taken into account, because the magnetic forces depend on the position of these moving parts. These positions, in turn, influence the magnetic field within the motor. Therefore, for full and suitable modeling, a link between the fields and motion must be established. At this end, only three-phase voltage applied to the terminal of the motor are required as known input value and phase current is evaluated as unknown value [16].

The voltage equation per each phase is:

$$
V_{a}=I_{a} R_{a}+L_{e} \frac{d l_{a}}{d t}+\frac{d \varphi_{a}}{d t}
$$

Where $V_{a}, I_{a}, R_{a}, \phi_{a}$, and $L_{e}$ are the input voltage, the current, the resistance, the flux linkage of each phase and the end-coil inductance, respectively. It should be noted, $L_{e}$ is calculated by using RMxprt toolbox in ANSYS Maxwell.

\section{MATERIALS AND METHOD}

The analysis of the induction motor was carried out using finite element analysis approach. The FEA technique includes the following procedures:

i. Modeling: This is the first step that require the physical dimensions and interconnections of the device to be described in 2-dimension.

ii. Meshing: The region is segmented into nonoverlapping sub-regions called 'Elements' connected via 'Nodes'. This part could be performed using one or a collection of different element types or meshing techniques.

iii. Solver: The numerical procedure to be used in the analysis is described and solution process is initiated.

iv. Post-processing: The desired quantities are either extracted or computed from the field quantities already obtained. The solution for the whole mesh is approximated using the interpolation function and the desired parameters or variables, derived from the solution are computed based on the solution in the entire domain. Additional computations might also be required for iterative algorithms that employ adaptive currents and adaptive mesh requirement.

The data of the motor are presented in Table 1. Figure 1 represents half of the machine transversal section in Maxwell 2D environment.

Figures 2 and 3 represent the stator and rotor slots geometry respectively.

\section{RESULTS AND DISCUSSIONS}

In the previous section, the model of the three phase squirrel cage induction motor was obtained and implemented in the ANSYS Maxwell environment. The simulation produced a number of results with respect to important variables of the induction motor. It is the objective of this section to discuss the results obtained and pave way for an informed conclusion. The results are divided into different sections.

Vol. 36, No. 4, October 2017 


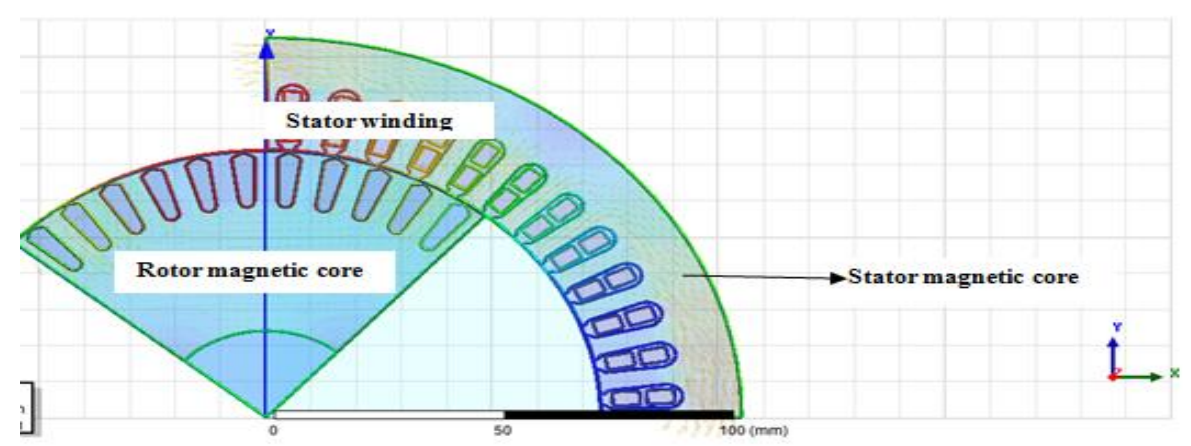

Figure 1: The computation domain

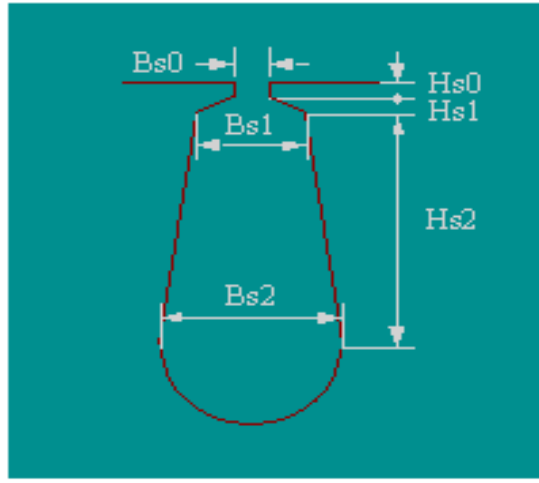

Figure 2: Stator slot geometry [17].

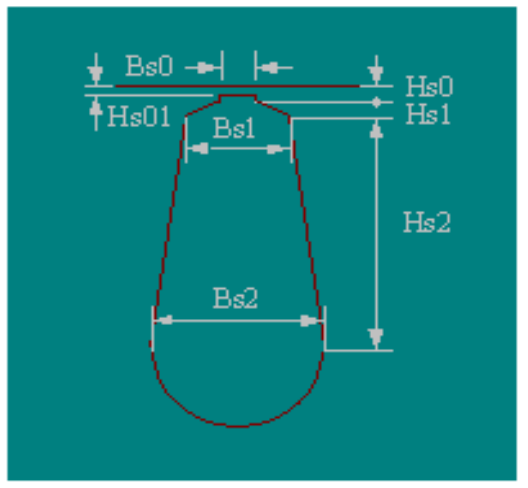

Figure 3: Rotor slot geometry [17].

Table 1: The machine data

\begin{tabular}{ll}
\hline Parameter & Value \\
\hline Output Power & $7.5 \mathrm{~kW}$ \\
Rated Voltage & $380 \mathrm{~V}$ \\
Winding connection & Wye \\
Number of poles & 4 \\
Rated speed & $1360 \mathrm{rpm}$ \\
Rated frequency & $50 \mathrm{~Hz}$ \\
Number of stator slots & 48 \\
Outer diameter of the stator & $210 \mathrm{~mm}$ \\
Inner diameter of the stator & $148 \mathrm{~mm}$ \\
Number of rotor bars & $44 \mathrm{bars}$ \\
Terminal Resistance & $0.669482 \mathrm{ohm}^{-}$ \\
End LeakageInductance & $0.000229044 \mathrm{H}$ \\
Estimated rotor inertia moment & $0.090125 \mathrm{kgm}^{2}$ \\
Coil pitch & 7 \\
\hline
\end{tabular}

Nigerian Journal of Technology,

\subsection{Motor Design}

Different materials with different magnetic properties can be used in designing the magnetic core of the motor. A comparison of three materials: Iron, Nickel and Cobalt was studied with respect to efficiency at $75^{\circ} \mathrm{C}$.

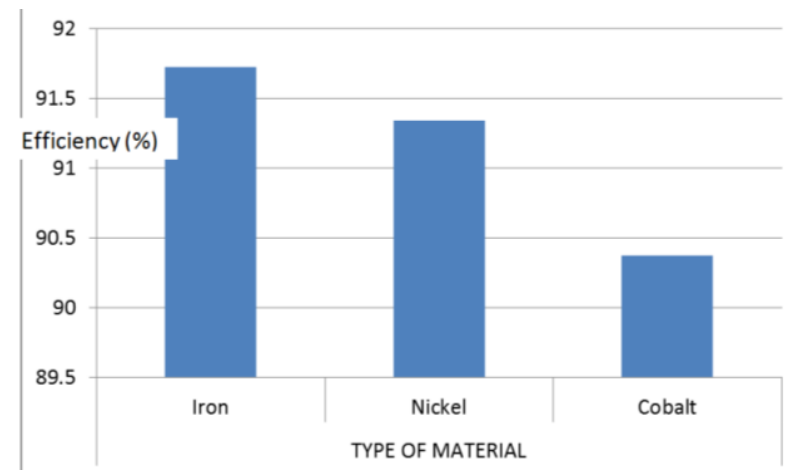

Figure 4: Effieciency with type of materials at $75^{\circ} \mathrm{C}$

It was observed in Figure 4 that iron at $75^{\circ} \mathrm{C}$ provided the best efficiency. A study of the losses occurring in the motor was also performed at the operating frequency of $50 \mathrm{~Hz}$ and reported in figure 5. At rated load, stray losses, frictional and windage losses, iron core losses, rotor copper loss and stator copper loss were observed to be $37 \mathrm{~W}, 38.3795 \mathrm{~W}, 153.386 \mathrm{~W}$, 248.141W and 410.352W respectively.

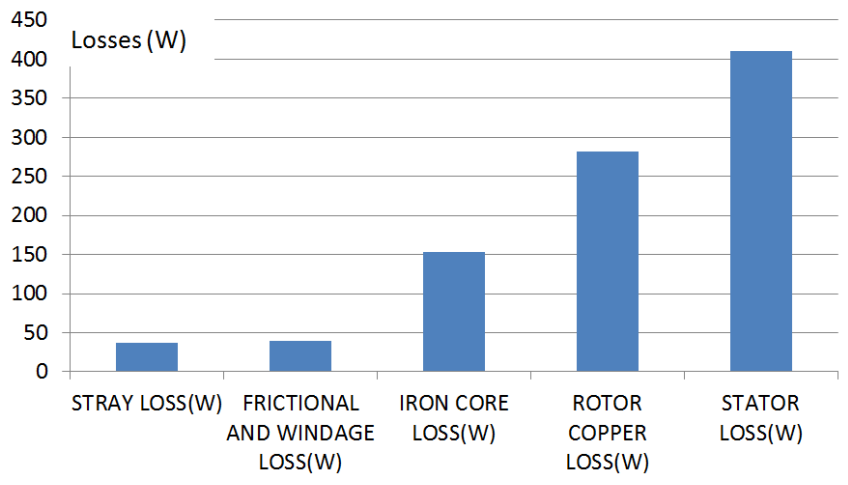

Figure 5: Losses with operating frequency of $50 \mathrm{~Hz}$ 


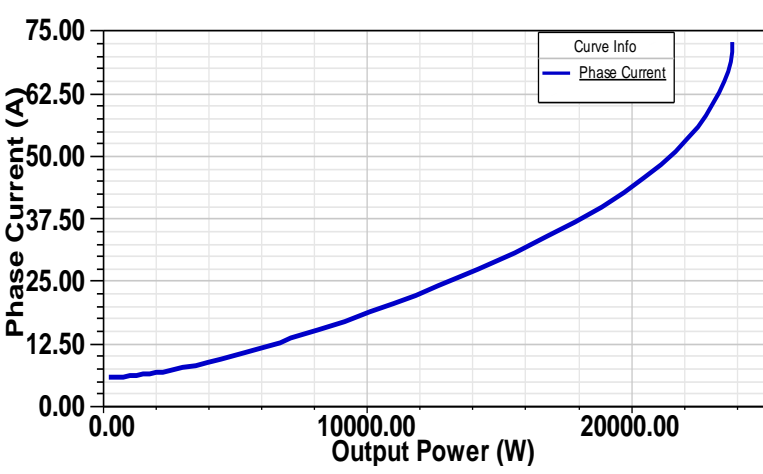

Figure 6: Phase Current with Output Power.

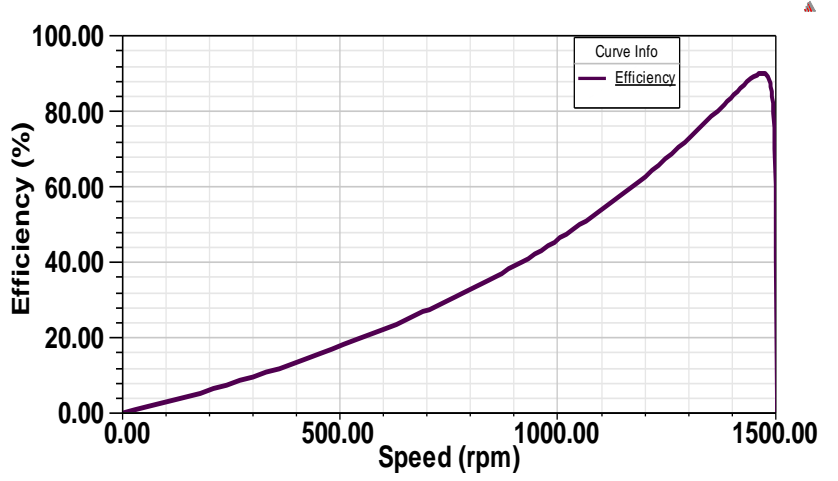

Figure 7: Efficiency with Speed

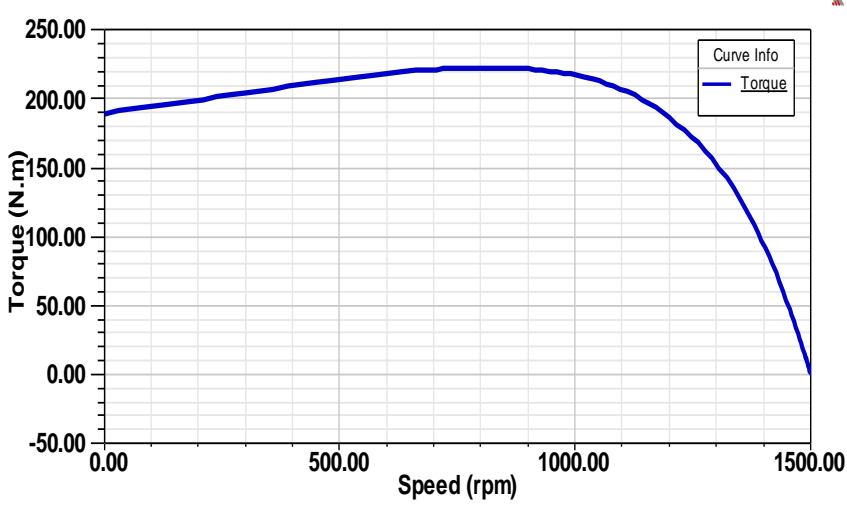

Figure 8: Torque with Speed

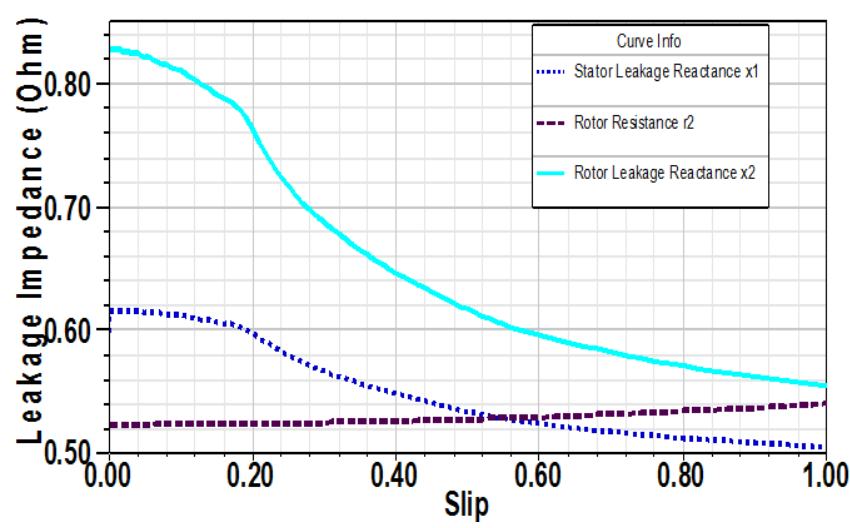

Figure 9: Leakage Impedance with Slip.

\subsection{Steady States}

The study of the stator phase current relationship with output power is shown in figure 5 . As to be expected, current increases with the output power. At the rated power of $7.5 \mathrm{~kW}$, the currents are $17.5 \mathrm{~A}$ at $75^{\circ} \mathrm{C}$. This will be a guide in the choice of stator winding insulation.

The efficiency-speed relationship was also studied and reported in figure 7. As to be expected, it is observed that the efficiency increased with the operating speed and peaks at the rated speed.

The study of torque-speed relations is also shown in figure 8. It shows that the torque at stall is $190 \mathrm{Nm}$ while at the rated speed, the torque is $130 \mathrm{Nm}$. Maximum torque of $225 \mathrm{Nm}$ occurred at $950 \mathrm{rpm}$. With emphasis on torque, the motor can operate at a wide range of speed between 0rpm and 1250rpm.

Another study made is the leakage impedance-slip relationship, which is reported in figure 9. Clearly, the slip affects the leakage impedance. The MATLAB basic fitting tool was used to obtain the trend equations which are as follows:

For Rotor Leakage Reactance, $\mathrm{X}_{2}$ :

$$
\mathrm{X}_{2}=-1.7 s^{4}+3.4 s^{3}-1.8 s^{2}-0.18 s+0.84
$$

For Stator Leakage Reactance, $\mathrm{X}_{1}$ :

$$
\mathrm{X}_{1}=-0.79 s^{4}+1.7 s^{3}-s^{2}+0.0022 s+0.62
$$

For Rotor Resistance, $\mathrm{r}_{2}$

$$
\begin{aligned}
r_{2}=-0.0085 s^{4} & +0.016 s^{3}+0.0079 s^{2}+0.00152 s \\
& +0.52
\end{aligned}
$$

\subsection{Dynamic States}

The motor was monitored at different loading conditions in order to predict its behaviors at such operations. The different loading conditions considered in this paper include:

- No-Load condition

- Rated Load condition

\subsubsection{No Load Condition}

Figures 10-13 give the characteristics of the cage motor on no-load operation.

Figure 10 shows the relationship between the no-load speed of the motor with time. Starting transient is clearly shown. The speed reached a peak value of about $1760 \mathrm{rpm}$ before it stabilized at $1500 \mathrm{rpm}$ in $0.16 \mathrm{~s}$. Expectedly, the slip of the motor is 0 .

Figure 11 shows the no-load torque-time characteristics of the induction machine. Expectedly, initial transients were observed and a steady state was attained after 0.16s. Figure 12 shows the phase A Current relationship with time of the motor under noload condition. The magnetic flux lines of the motor at 1s on no-load condition is shown in Figure 13.

Figure 13 shows only the one-quarter of the motor geometry. This model is used because it clearly presents how the flux links the slots. 


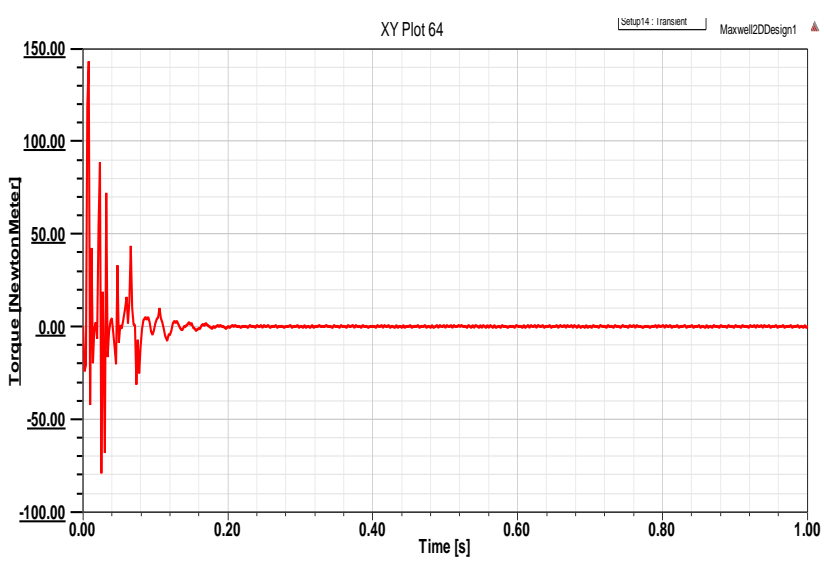

Figure 11: Torque with Time on No-Load

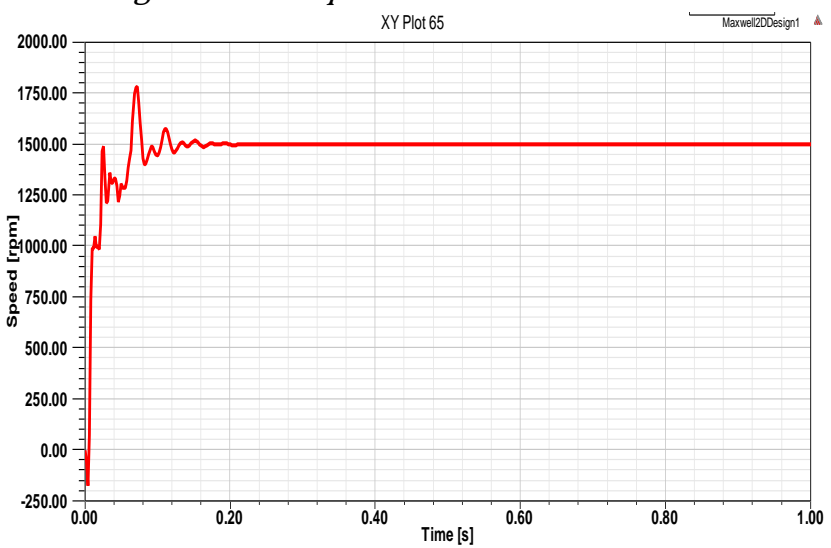

Figure 10: Speed with Time on No-Load

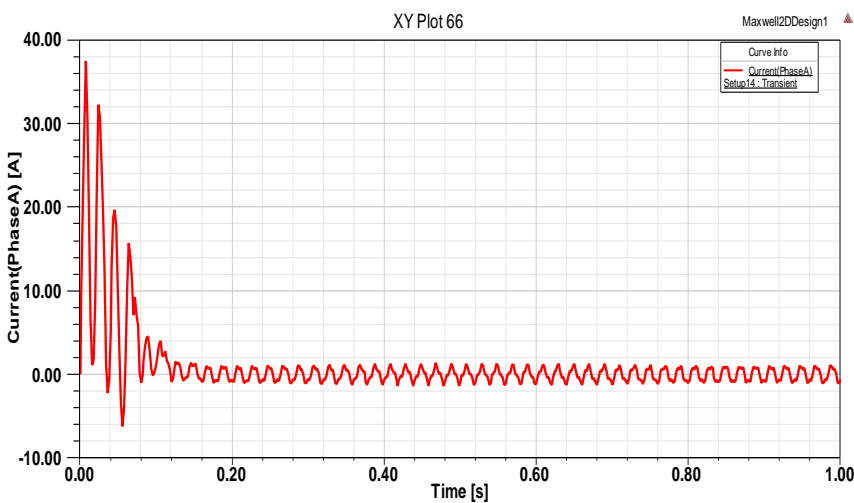

Figure 12: Phase A Current with Time on No-Load

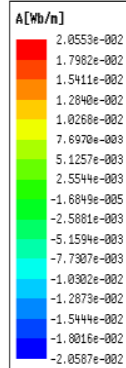

Time $=15$
Speed $=1481.114581 \mathrm{rpm}$

Figure 13: Flux distribution in the cage motor on $\mathrm{No}$ Load

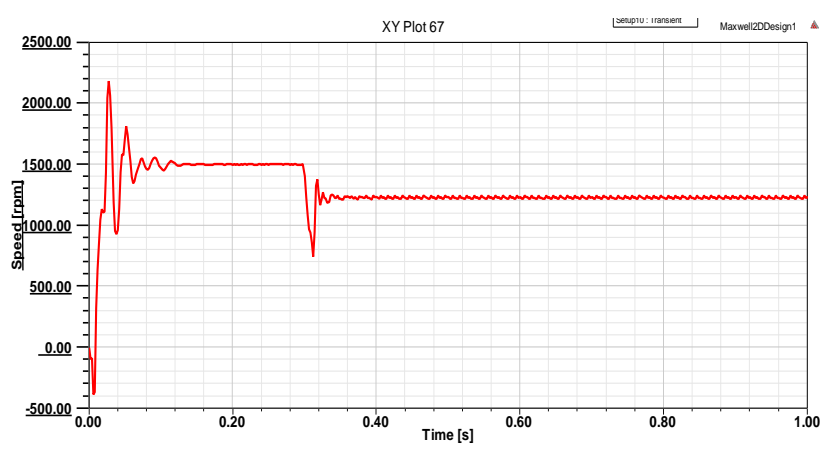

Figure 14: Speed with Time at Rated load.

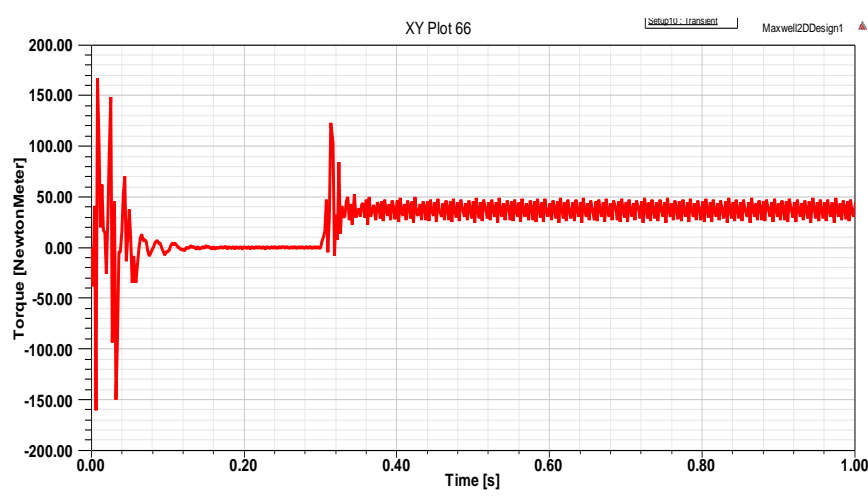

Figure 15: Torque with Time at Rated load.

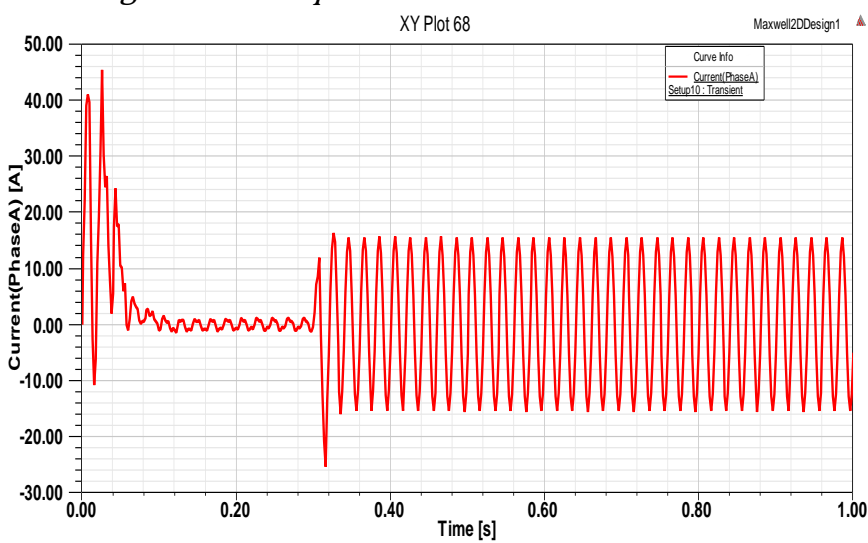

Figure 16: Phase A Current with Time at Rated Load.
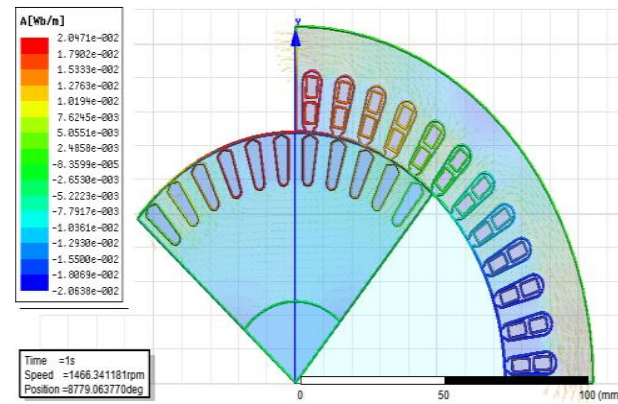

Figure 17: Flux lines at Rated Load condition.

\subsubsection{Rated Load Condition}

In this paper, a rated load of $26.33 \mathrm{Nm}$ was introduced at $0.3 \mathrm{~s}$. The behavior of the motor was monitored as seen in Figures 14-17. Expectedly, the speed of the motor dropped to $750 \mathrm{rpm}$ immediately the load was 
introduced at $0.3 \mathrm{~s}$. The speed stabilizes at $1250 \mathrm{rpm}$. From figure 14, the slip of the motor was recorded as 0.167 . It can be observed that the slip (0.167) at rated load is greater than the slip (0) on no-load. Figures 1516 show the effects of the load on the torque and current characteristics of the motor when it is applied at 0.3s. The flux lines at rated load is shown in Figure 17.

\section{CONCLUSION}

In this paper, a three-phase, 4-pole, Y-connected, 7.5 $\mathrm{kW}$ squirrel cage induction motor with double layer winding was analyzed. The motor is fed by a $380 \mathrm{~V}$, $50 \mathrm{~Hz}$ sinusoidal source at a full load. The motor possesses 48 stator slots and 44 rotor slots. Also, current flowing through a coil in each slot is assumed to distribute sinusoidally.

The design and analysis has been performed on the ANSYS Rmxprt and Maxwell platform. The geometry and parameters of the motor have been obtained by Rmxprt and were transferred into the Maxwell 2D for further transient analysis.

A study of the losses occurring in the motor performed at the operating frequency showed that stator copper loss and rotor copper loss were higher than the other losses at $50 \mathrm{HZ}$. The motor efficiency based on material design was also studied at $75^{\circ} \mathrm{C}$. The materials considered in this paper are iron, nickel and cobalt. It was observed that iron at provided the best efficiency than other materials. The steady and dynamic states characteristics of the motor at rated load and on noload conditions were observed. The flux levels at these loading conditions were also monitored. From the above results, it can be inferred that FEA approach is highly suited for machine analysis under steady and dynamic conditions.

\section{REFERENCES}

[1] Patel, H. K. "Steady State and Transient Performance Analysis of Three Phase Induction Machine using MATLAB Simulations", International Journal of Recent Trends in Engineering, Vol.1, Number 3, pp 266-270, 2009.

[2] Boldea, I. and Nasar, S. A."Unified treatment of core losses and saturation in the orthogonal-axis model of electric machines", IEE proceedings, Vol.134, Number 6, pp 355-363, 1987.

[3] Mittle, V. N. "Stability Analysis of a constant Torque static Slip-Power-Recovery Drive", IEEE Transactions on Industry Applications, Vol. IA-16, Number 1, pp 119-126, 1980.
[4] Krause, P. C. Analysis of Electric Machinery, McGraw-Hill Book Company, New York, 1986.

[5] Okoro, 0. I. "Steady State and Transient Analysis of Induction Motor Driving A Pump Load", Nigerian Journal of Technology, Vol. 22, Number 1, , pp 46-53, 2003.

[6] Binns, K. J. and Lawrenson P. J. Analysis and computation of electric and magnetic field problems, New York, Pergamon Press, 1973.

[7] Brebbia, C. A. and Dominguez, J. Boundary elements: an introductory course, Southhampton, Boston: Computational Mechanics Publications; New York: Co-published with McGraw-Hill, 1992.

[8] Salon, S. J. Finite element analysis of electrical machines, Kluwer Academic Publishers, 1995.

[9] Reece, A. B. J. and Preston, T.W. Finite element methods in electrical power engineering, Oxford University Press Inc., New York, 2000.

[10] Williamson, S., Lim, L.H and Robinson, M.J. "Finiteelement models for cage induction motor analysis", Conference Record of the IEEE Industry Application Society Annual Meeting, vol. 1, pp. 2330, 1989 .

[11] Chari, M. V. K. and Silvester, P. "Analysis of turboalternator magnetic fields by finite elements", IEEE Transactions on Power Apparatus and Systems, Vol. 90, Number 2, pp 454-464, 1971.

[12] Hannalla, A. Y. and MacDonald, D. C. "Numerical analysis of transient field problems in electric machines", IEE Proceedings, Vol. 123, Number 9, pp 893-898, 1976.

[13] Silvester, P. P. and Ferrari, R. L. Finite Elements for Electrical Engineers, Cambridge University Press, London, 1996.

[14] Jabber, M. A., Phyu H. N., Liu Z. and Chao B. "Modelling and Numerical Simulation of a Brushless Permanent Magnet DC Motor in Dynamic Conditions by Time-Stepping Technique", IEEE Transactions on Industry Applications, Vol.40, Number 3, pp 763-770, 2004.

[15] Arkkio, A. Analysis of Induction Motors Based on the Numerical Solution of the Magnets Field and Circuit Equations, Doctoral Thesis, Faculty of Electrical Engineering, Helsinki University of Technology, 1987.

[16] Abunike, E. C. and Okoro, O. I. "Finite Element Analysis of a $7.5 \mathrm{~kW}$ Asynchronous Motor under Intermittent Loading", Umudike Journal of Engineering and Technology, Vol. 2, Number 2, pp 8-15, 2016.

[17] Maxwell 2D/RMxprt FEA-Simulation Program. Ansoft Corporation, Munich, 2010. 